Prevention of coronary heart disease

I MCD G Stewart, FRCP; J Yudkin, FRCP . 1207

Myocardial infarction

R Lefever, MRCGP. . . . . . . . . . . . . . 1208

Regression of atherosclerosis

H D Beckett, MRCPSYCH . . . . . . . . . . . 1208

Sociological realities

F M Martin, PHD. .

Caesarean section and respiratory

distress syndrome

R Pearson, MRCP; C R Whitfield, FRCOG. . . . 1209

Oestrogens as a cause of endometrial

carcinoma

I D Cooke, FrCOG. . . . . . . . . . . . . 1209

The community physician of the future

D Cameron, MB; C R Haines, MFCM. . . . . 1210

Driving and medical fitness

G W Roberts, FFCM. . . . . . . . . . . . . 1210

Non-accidental poisoning and child

abuse

$\mathrm{D}$ Pickering, MRCPED, and others; J P

Osborne, MRCP.................1210
Induction and perinatal death

J Walker, FRCOG................

Nit-picking?

W F Whimster, MRCP; C M Heath, MD,

DOMs ..................

In defence of the under-40s

J S Bradshaw, MB.................. 1212

"Automatic" sun-glasses: a warning

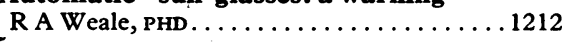

S̄kin contact pressures

P A Isherwood, MB, and others.......1212

Low-dosage treatment with tetrabenazine

R Schneider, FRCPED, and others....... 1212

SI units in France

A N G Clark, FRCP............... 1213

Medical and surgical emergencies in

divers

R J Knight, fFARAcs. . . . . . . . . . . 1213

Cross-sensitivity between practolol and

other beta-blockers?

F J Zacharias, FRCP...

Thoracic discs are different

J D Miller, MRCGP. . . . . . . . . . 1213
Design of clinical trials

I S Muir, MB . . . . . . . . . . 1213

Phenobarbitone for convulsions in

children

Sheila J Wallace, MRCPED..............1213

Erythema nodosum and brucellosis

G A MacGregor, MD . . . . . . . . . 1214

Postgraduate medical education in the

EEC

R Brearley, FRcs ...................

Should doctors strike again?

D S Short, FRCP, and others . . . . . . . . 1214

Non-contributory invalidity pension

C G Bell, MRCGP..................1214

Trade unions and private practice

A J M Hargreaves, MrCs............. 1215

Points from ietters What's in a name? (C

Cohen); Smoking and congenital deformities

(J P Welch); Not so double-blind? (L G

Marquis); Oestrogens as a cause of endometrial cancer (H S Jacobs); Multiple copies of applications (C Roberts); Profession and Government

(I M Quest); Trade unions and private practice

(J S Horsley)................ 1215

Correspondents are urged to write briefly so that readers may be offered as wide a selection of letters as possible. So many are being received that the omission of some is inevitable. Letters should be signed personally by all their authors.

\section{Prevention of coronary heart disease}

SIR,-In your assessment (10 April, p 853) of the joint report by the Royal College of Physicians and the British Cardiac Society ${ }^{1}$ on the prevention of coronary heart disease you say that "it seems that coronary:artery disease persists as a legacy of past years of hypertension." Such indeed is the widely accepted view despite a notable lack of support from studies in pathology and arteriography. My own feeling is that it rests largely upon confused interpretations of the term coronary heart disease (CHD) and of hypertension as a "risk factor."

The joint report defines $\mathrm{CHD}$ as "myocardial infarction, angina pectoris and sudden death," the clinical appearances that have been shown in the Framingham studies ${ }^{2}$ to increase in accordance with a rise in blood pressure. The authors conclude that this finding "illustrates how well CHD risk can be identified" by pressure recordings. But angina is the major element in this version of CHD, in women exceeding myocardial infarction and sudden death combined. And hypertension can provoke angina irrespective of the nature and origin of disease in the coronary arteries. The Framingham findings, therefore, can do no more than show hypertension as a reversible risk factor capable of eliciting the angina element of CHD by variable association, as also can obesity, and in no sense as a proved influence creating permanent injury. Moreover, many of the victims of angina have never been hypertensive. Thus the presentation of this symptom in association with increasing hypertension can tell us nothing of those developments in morbid anatomy that are fundamental to the aetiology of CHD and nothing, therefore, to justify the claim that coronary atheroma arises and "persists as a legacy of past years of hypertension." In order to establish such a relationship it would be necessary to demonstrate that a gradation of morbid change in these arteries increases in parallel with a rise of pressure. Without this evidence the implication that hypertension has been shown by epidemiological study to be a factor in the complex processes of coronary atherogenesis must rest upon a false assumption.

On the other hand both the Framingham reports and the work of. Wilhelmsen and his colleagues, $^{3}$ who exclude angina from their understanding of $\mathrm{CHD}$, have shown that hypertension is significantly related to myocardial infarction and sudden death, easily recognisable, irreversible events that provide acceptable end points for assessing comparative incidence.

It would seem, therefore, that there is still good reason to accept Pickering's view ${ }^{4}$ that hypertension is at most no more than "lowly correlated" with coronary atheroma, despite its proved effects as a progenitor of arterial damage elsewhere in the body. Nonetheless, it may well be an important precipitating factor in the onset of myocardial infarction. From this it would appear to follow that the best immediate hope of lessening the incidence of myocardial infarction in hypertensives may well lie in appropriate anticipatory hypotensive and antidysrhythmic treatment aimed at averting the acute attack.

Department of Medicine,

I MCD G STEWART

Victoria Hospital, Joint Working Party, fournal of the Royal College of
Physicians of London, 1976, 10, 213 .

2 Kannel, W B, and Dawber, T R, British fournal of Hospital Medicine, 1974, 11,508 .

Wilhelmsen, L, Wede 1, H, and Tibblin, G, Circulation, 1973, 49, 950 .

Pickering, $G$ W, in Antihypertensive Therapy, ed F Gross, p 147. Berlin, Springer, 1966.
SIR,-As could have been foreseen, the Royal College of Physicians report $^{1}$ has been interpreted as saying that people can protect themselves against coronary heart disease (CHD) by changing the amount and type of fat in their diets. The British Heart Foundation now offers" a "recipe for avoiding heart disease" in the form of their low-cholesterol cookery book.

Less than two years ago a DHSS committee ${ }^{3}$ did not recommend an increase in the proportion of polyunsaturated fats as the RCP does. Both committees considered the same evidence, including the dietary trials carried out in Los Angeles and in Helsinki designed to test the effect of substituting "soft fats" for "hard fats." It has been calculated ${ }^{4}$ that such trials, if carefully controlled, could not produce acceptable evidence unless at least 19000 subjects were involved; the trials quoted each used only a few hundred subjects and the RCP report admits that they "have serious defects." Yet it decided that the results support its view of the beneficial effects of increasing the proportion of polyunsaturated fats in the diet.

A close look at what the report has to say about nutritional matters does not increase confidence in its judgment as to the role of diet in CHD. It says, "In order to reduce our total fat intake and particularly the saturated fats ... (a) Eat less meat and fewer egg yolks ..." Egg yolks contain a rather higher proportion of polyunsaturated fat to saturated than does the average UK diet ; moreover, even if we stopped eating eggs altogether the average total fat in out diets would be reduced only from $111 \mathrm{~g}$ a day to $108 \mathrm{~g}$. The report says that "[dietary] sugar does not raise the plasma cholesterol level in man." There are now several publications from different countries demonstrating 